\title{
A study of the maxillary and sphenopalatine arteries in the pterygopalatine fossa and at the sphenopalatine foramen
}

\author{
Tor Chiu
}

Laboratory of Human Anatomy, University of Glasgow, Glasgow, Scotland, United Kingdom

\begin{abstract}
SUMMARY Objectives: Arterial ligation remains a key option in the treatment of persistent epistaxis and clarification of the arterial configuration of the distal maxillary/ sphenopalatine artery is important for understanding the rationale behind current surgical treatments. Greater understanding of the arterial anatomy will reduce the risk of technical failures and improve the reliability of surgical interventions for persistent epistaxis and will also be useful for surgeries involving the pterygopalatine fossa.
\end{abstract}

Study Design: Anatomical study in cadavers.

Methods: This is an anatomical study of 128 cadaveric tissue blocks containing the pterygopalatine fossa. In total, 118 tissue blocks were microdissected using a Watson-Barnet dissecting microscope. Ten injected tissue blocks were cleared by the Spalteholz technique. Photographic records were made.

Results: Analysis demonstrated three common configurations of the maxillary artery in the pterygopalatine fossa: a single looped form (18\%) and two double-looped forms, 'E' (51\%) and ' $M$ ' (31\%). The maxillary artery bifurcates before the sphenopalatine foramen in 105 cases (89\%). The sphenopalatine foramen lies at the posterior end of the middle turbinate; in 58\% of cases it lies in both the superior and middle meati. Asymmetry in the size of the maxillary arteries was uncommon; only 3\% could be described as 'dominant'.

Conclusions: The arterial configuration of the maxillary artery in the pterygopalatine fossa can be complex but may be classified into one of three forms. Some configurations may be more liable to lead to difficulties with branch identification during surgical treatment of epistaxis particularly in combination with an inadequate osteotomy. Clinicians should expect to find more than one vessel exiting the sphenopalatine foramen and actively search for these during surgery. Asymmetry in the maxillary/ sphenopalatine arteries is not common and contralateral ligations are not indicated.

Key words: epistaxis, maxillary artery, arterial ligation, sphenopalatine artery, sphenopalatine foramen, pterygopalatine fossa

\section{INTRODUCTION}

Epistaxis is the most common ENT emergency ${ }^{(1)}$ and in rare cases can be fatal. Difficulty in visualising the posterior nasal cavity hinders the precise identification and specific treatment of the bleeding site. Traditionally, packing has been the commonest modality of initial treatment ${ }^{(2)}$ and those continuing to bleed or rebleed despite this non-specific treatment would be deemed 'persistent'. Further repacking under general anaesthesia (with or without septal surgery to improve access), embolization ${ }^{(3)}$ or ligation of the maxillary artery ${ }^{(4,5)}$ or ligation/cautery of the sphenopalatine artery ${ }^{(6)}$ have all been advocated for further treatment, depending on the preference of individual centres.
Transantral ligation of the maxillary artery was once regarded as the most effective procedure for persistent posterior epistaxis ${ }^{(7)}$ although it still had a significant reported failure and complication rates of around $10-17 \%$ on average ${ }^{(3)}$. Speculation on the reasons for unexplained failure of arterial ligation to control epistaxis was a recurring theme in the literature; some suggested inadequate technique, anastomotic anterograde filling, anastomotic retrograde filling ${ }^{(7)}$ and aberrant vessels ${ }^{(8)}$. Uncertainty regarding the bleeding site and misconceptions of nasal vascular anatomy and physiology can lead to the proposal of additional and or alternative procedures for persistent bleeding. Revisiting the regional anatomy is appropriate with the 
establishment of endoscopic techniques of arterial ligation and or cautery as the first treatment option with lower rates of failure and complications.

\section{MATERIALS AND METHODS}

Sixty-four cadaveric heads (yielding 128 pterygopalatine fossae) belonging to the Laboratory of Human Anatomy of the University of Glasgow were used for this anatomical study.

Dissection and microdissection $(n=118)$

Tissue blocks containing the posterior antral wall and pterygopalatine fossa were taken from cadavers embalmed in the standard manner. The posterior portion of the lateral nasal wall was included to preserve the sphenopalatine foramen. The posterior antral wall was then completely osteotomised in a piecemeal fashion and the periosteum removed to reveal the vessels and nerves embedded in fibro-fatty tissue. Microdissection of the vessels of the pterygopalatine fossa was carried out with a Watson-Barnet dissecting microscope.

Photographic records were made at various stages of dissection to demonstrate the position and size of the vessels. Measurements of the diameter of the maxillary artery and its branches at various points and the dimensions of the sphenopalatine foramen were taken using vernier calipers accurate to $0.1 \mathrm{~mm}$.

\section{Spalteholz clearing of injected specimens $(n=10)$}

5 other cadavers were injected with latex-Indian ink at the time of embalming. The 10 tissue blocks taken from these were then 'cleared' by the Spalteholz technique. This process involves fixation of decalcified blocks in a series of alcohol/ benzol solutions before immersion in a methylsalicylate/ benzyl benzoate mix which renders the tissue transparent and injected vessels are visible 'in situ'.

\section{RESULTS}

\section{Pterygopalatine fossa}

The pterygopalatine fossa approximates to the shape of a funnel flattened in the coronal plane. The fossa is bounded by the body of the sphenoid superiorly, and communicates with the ptergyomaxillary fissure laterally. The lateral wall of the nose forms the medial boundary whilst the sphenopalatine foramen connects the two in the form of a relatively long canal or fissure rather than a simple 'window'. The pterygopalatine fossa occupies the upper half/ two thirds of the posterior antral wall. It is wider superiorly, and then narrows down inferiorly with the apex pointing downwards into the canal for the greater palatine artery and nerve. The most superficial structure of the fossa is an inconstant thin-walled pterygopalatine vein $(21 \%$ absent both sides and 59\% absent on one side). The third part of the maxillary artery and its branches are tightly packed within the pterygopalatine fossa forming a layer superficial to the nerves (Figure 1).

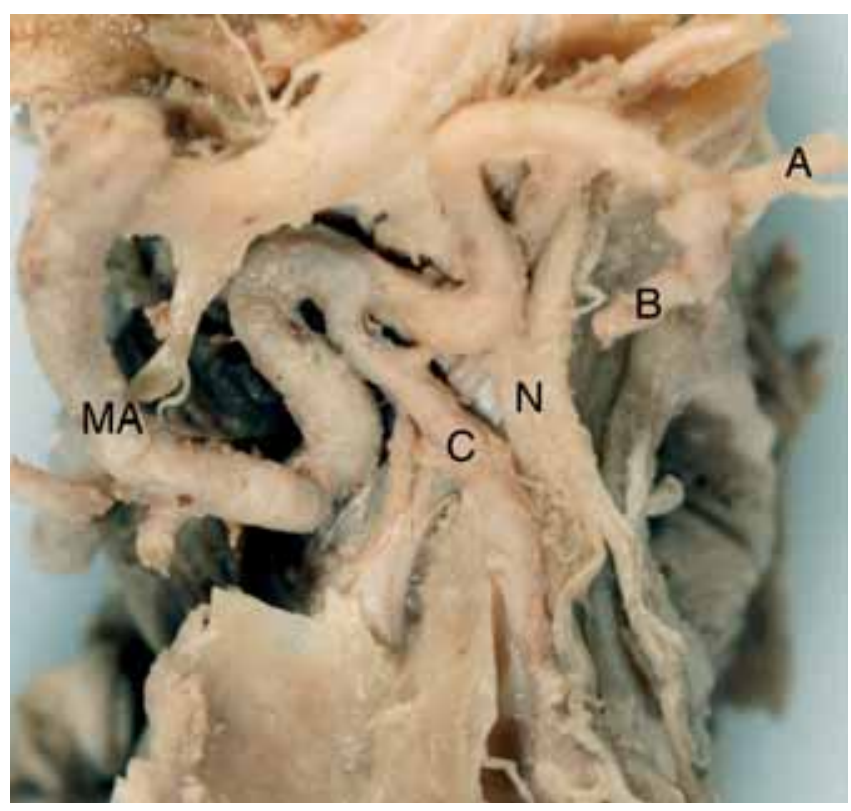

Figure 1. Photograph of the contents of the pterygopalatine fossa in situ demonstrating main maxillary artery (MA), sphenopalatine (A), posterior nasal artery (B), greater palatine artery $(C)$ and nerve $(N)$.

\section{Arterial Configuration}

The use of isolated tissue blocks allowed comprehensive dissections of the arteries in the pterygopalatine fossa and around the sphenopalatine foramen. Analysis of the patterns of arterial branching demonstrated two general configurations: single looped (looser form) (18\%) and double looped (tighter form) $(82 \%)$. In the latter form, the loops were orientated either on top of each other like an 'E' or 'epsilon' (51\%), or side by side like a 'M' shape (31\%) (Figure 2a-c).

\section{Sphenopalatine Foramen}

The opening of the sphenopalatine foramen is a vertically orientated oval at the end of a 4-7 mm canal located in the superomedial corner of the triangular pterygoplatine fossa. The mean vertical diameter is $6.2 \mathrm{~mm}(4.5-7.5 \mathrm{~mm})$ and the mean horizontal diameter is $5.1 \mathrm{~mm}(3.5-6.0 \mathrm{~mm})$.

The sphenopalatine foramen was consistently found in the lower part of the superior meatus at the posterior end of the attachment of the middle turbinate on the lateral nasal wall with some variation with respect to its exact relation to the middle turbinate. The inferior portion of sphenopalatine foramen lies below the posterior end of the line of attachment of the middle turbinate (ie partly in the middle meatus) and crista ethmoidalis in $68(58 \%)$ of the cases. In 6 cases (5\%) there is a broader bony bridge across separating the main foramen from the smaller accessory foramen that is usually placed inferior to the main foramen; only one of these accessory foramina transmitted a small vascular bundle.

The maxillary artery terminates as the sphenopalatine artery and the posterior nasal artery (Terminological Anatomica) 


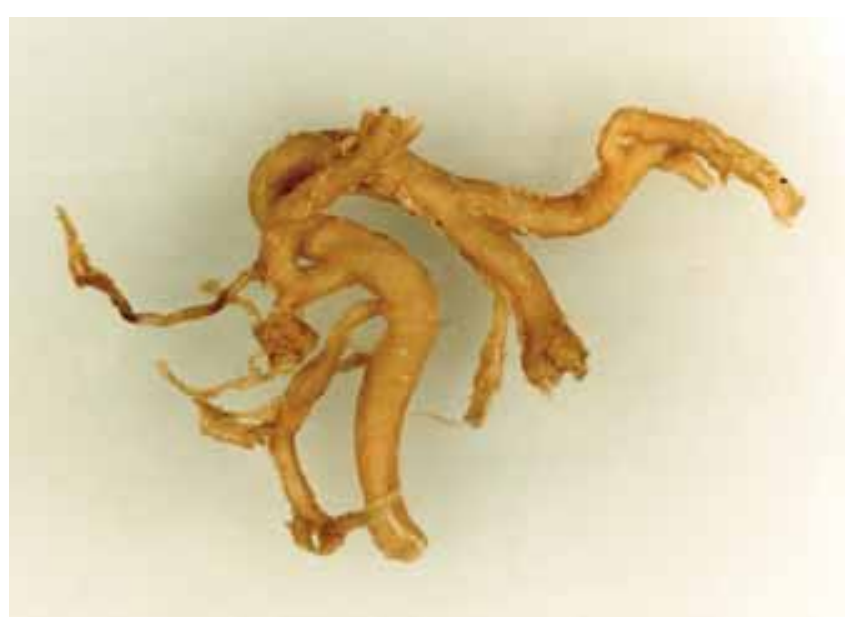

Figure 2. After the third part of the maxillary artery in the pterygopalatine fossa had been dissected out in situ, representative cases were removed for improved clarity during photography.

a). Single-looped configuration. Looser single-looped configuration $18 \%$.

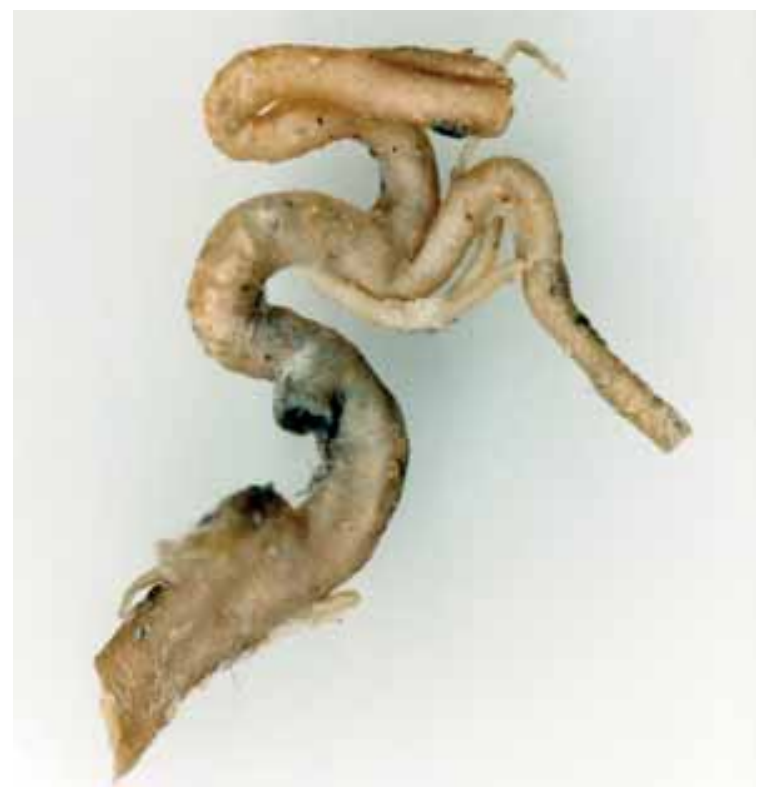

Figure 2(b). More tightly packed a'E' form double loop configuration $57 \%$.

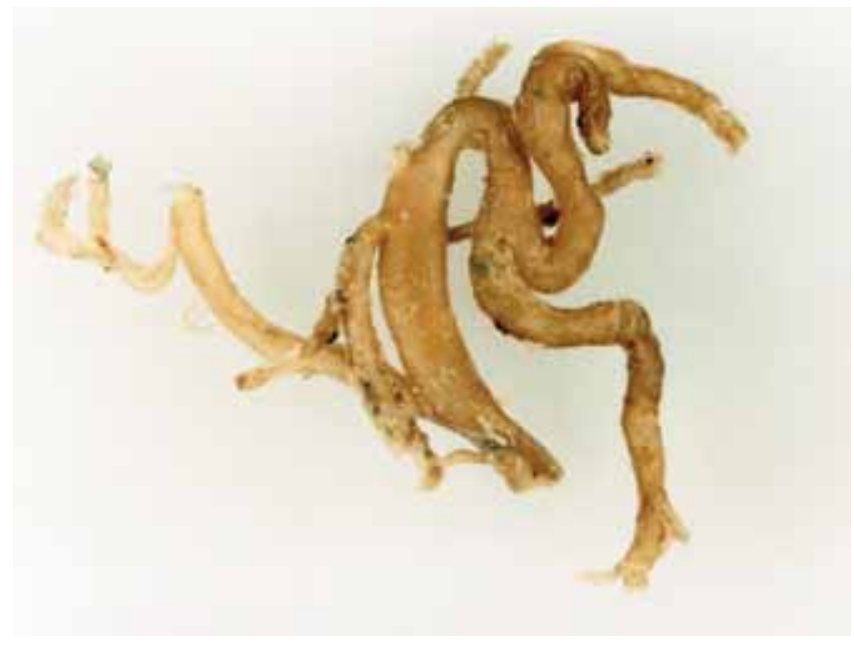

Figure 2(c). 'M' form double loop configuration 31\%. within the pterygopalatine fossa (that is before the sphenopalatine foramen) in 105 (89\%). Of these, there were two, three and four branches in 81, 22 and 2 cases respectively (69\%, 19\% and $2 \%$ respectively). This means that in most cases, more than one vessel will traverse the sphenopalatine foramen and this must be borne in mind when dissecting the mucosa around the foramen/ foramina during endoscopic techniques. It was found that the maxillary artery is less likely to divide before the sphenopalatine foramen (38\%) if it was in a single looped (loose) form in the pterygopalatine fossa.

\section{Symmetry and size of the maxillary arteries}

There was little difference in the size of the maxillary arteries between right and left sides. The mean for the left maxillary artery was $4.50 \mathrm{~mm}$ and the right $4.62 \mathrm{~mm}$ (Table 1). Although more than half (59\%) of the maxillary arteries were $4.0 \mathrm{~mm}$ or less in size on one side or both, only a small number of these (3) showed a significant (more than 1.5 times) size difference between left and right sides that would fit into a definition of having 'dominant' maxillary arteries ${ }^{(9)}$.

Spalteholz clearing

These preparations confirmed the findings of the pterygopalatine fossa from conventional microdissections provided novel demonstrations of the 'in-situ' configuration of the arteries in 3 dimensions.

Table 1. Average diameter of arteries ( $\mathrm{mm})$. The mean diameters of the arteries on the left and right sides are given in the first row. The number of 'asymmetric' arteries where one side is $10 \mathrm{~mm}$ or $20 \mathrm{~mm}$ larger than the other side is given in the second and third rows respectively.

\begin{tabular}{lcc}
\hline $\mathbf{N}=\mathbf{1 1 8}$ & Left & Right \\
\hline Mean & 4.50 & 4.62 \\
$>10 \mathrm{~mm}$ greater than other side & 8 & 11 \\
$>20 \mathrm{~mm}$ greater than other side & 1 & 2 \\
\hline
\end{tabular}

\section{DISCUSSION}

This study includes the largest series of dissections of the distal maxillary artery and its branches in the pterygopalatine fossa and around the sphenopalatine foramen. Comprehensive microdissection was very time consuming but was preferred over 'xylene dissection' ${ }^{(10)}$, which was found to be only partially effective and there were health and safety concerns. The arterial configurations were convoluted and complex with loops and multiple branches, making it potentially difficult to definitively identify individual branches at the time of surgery ${ }^{(8)}$. They have been described as being very variable with peaks and troughs of up to $15 \mathrm{~mm}$ with no discernible pattern ${ }^{(11)}$. However this study has shown that the configurations can be classified into one of three types: a single looped form, and ' $\mathrm{E}$ ' and 'M' double looped forms. The 'M' form with two vertically stacked loops can be particularly misleading when combined with an inadequate osteotomy. Metson ${ }^{(7)}$ advocates the 
removal of the entire posterior wall to improve visualisation of the vessels of the pterygopalatine fossa. Pearson ${ }^{(8)}$ stated that there was increasing tortuosity with age in his study of 21 specimens, however a consistent trend could not be demonstrated in this study.

In the majority of cases there will be 2 or more vessels at the sphenopalatine foramen, these will need to be found at the time of operation during endoscopic ligation/ cautery and dealt appropriately. This figure is in agreement with most studies ${ }^{(12,13)}$ although O'Flynn ${ }^{(14)}$ found that there was usually only a single artery at sphenopalatine foramen. Comprehensive microdissections though time-consuming have an advantage over studies that rely on injections as the vessels may be unfilled in such cases ${ }^{(13)}$. The sphenopalatine foramen lies just above the level of the attachment of the middle turbinate but the vessels first run downwards in the mucosa of the lateral nasal wall meaning they are accessible by 'inferior' approaches to the sphenopalatine foramen. Studying cadavers rather than relying on osteologic features of skulls ${ }^{(19)}$ that could be subject to artefactual damage, improves the reliability of the observations. The sphenopalatine foramen has a variable relationship to the posterior end of middle turbinate and has a variable number of vessels passing through it - these variations are important to bear in mind in practice.

Our study also demonstrates that the maxillary arteries are generally symmetrical in size if not configuration. One study ${ }^{(9)}$ had found asymmetry in 6 of 12 specimens, with a dominant maxillary artery defined as one side being 1.5 times the diameter of the contralateral artery. It was proposed that if maxillary arteries smaller than $4 \mathrm{~mm}$ were found on one side, the contralateral side should be also be ligated on the basis that the contralateral vessel would be bigger in compensation and thus also more likely to refill the bleeding point. This highlights several misconceptions in nasal vascular anatomy/ physiology.

Firstly, if a particular vessel is abnormally small, it will be compensated by ipsilateral neighbouring vessels, rather than the corresponding contralateral vessel - this follows from their embryological development and has been elegantly shown in dissections of the arteries of the face and confirmed by angiography ${ }^{(15)}$. In this study, 59\% of the maxillary arteries would be deemed 'small' yet only 3 cases would be consistent with a definition of 'dominant artery' demonstrating that contralateral compensation is not commonly seen in the nasal cavity.

Secondly, the aim of arterial ligation in epistaxis is simply to reduce pressure in the bleeding vessel sufficiently to allow the clotting (and then healing) processes to occur and not to totally abolish flow, otherwise ischaemic necrosis would be a common consequence (there is a single case report of inferior turbinate necrosis after endoscopic ligation of the sphenopalatine artery in this study ${ }^{(16)}$. Consequently, the technique is expected to fail in a proportion of cases when the reduction in pressure is insufficient. This point has been picked up by some authors in this study ${ }^{(17)}$, but there still seems to be the need to invoke other factors to account for 'unexplained failures' such as 'aberrant pharyngeal arteries' or contralateral anastomoses.

For our analysis, we classify arteries in the nasal cavity as being either first or second order vessels with respect to the bleeding point. First order vessels would be vessels whose anatomic territories are adjacent to that of the bleeding vessel and whose dynamic territories would potentially overlap the bleeding point. Thus, in the commonest scenario where bleeding comes from sphenopalatine artery, the first order vessels would be the anterior and posterior ethmoidal arteries (internal carotid artery), greater palatine artery (external carotid artery) and septal branch of superior labial artery (external carotid artery). It is the flow in these vessels that would be most likely to contribute to continuing perfusion of the territory of the sphenopalatine artery territory and continued bleeding. This is borne out by angiographic studies ${ }^{(3,18)}$. Thus logically AEA ligation may be complementary to ligation of the maxillary/ sphenopalatine artery ${ }^{(19)}$ but its effectiveness would be difficult to predict, particularly since the AEA is absent in $14.3 \%{ }^{(20)}$. Second order vessels are those that (potentially) connect with first order arteries. However as, they are more distant from the bleeding point, and are separated by further set of choke vessels (physiological or anatomical), then simple laws of physics dictate that they would contribute considerably less to reperfusion of the bleeding point at least in the acute phase. These include vessels that have been implicated in previous studies such as the pharyngeal branch (small in calibre and travels through a narrow bony canal) and any contralateral anastomoses eg greater palatine to greater palatine artery or labial-to-labial artery, etc. That is, it is logical to treat vessels in the nose wherever possible, as close to the bleeding point as possible - ligation of the maxillary artery would mean that subsequent angiography or embolization would be less effective if needed.

Table 2. Results of articles reporting on results of transantral ligation. (12 papers, those not reporting a complication rate were excluded). For this analysis, the success rate is generally defined as no re-bleeding requiring surgical intervention in the same admission.

\begin{tabular}{lcccc}
\hline Author & Year & $\begin{array}{c}\text { Number } \\
\text { of patients }\end{array}$ & $\begin{array}{c}\text { Success } \\
\text { rate } \%\end{array}$ & $\begin{array}{c}\text { Complications } \\
\%\end{array}$ \\
\hline Chandler $^{(4)}$ & 1965 & 21 & 100 & 1 \\
Lofgren $^{(21)}$ & 1971 & 8 & 100 & 0 \\
Rosnagle $^{(5)}$ & 1973 & 50 & 90 & 16 \\
Montgomery $^{(22)}$ & 1980 & 60 & 85 & 3 \\
McDonald $^{(23)}$ & 1980 & 46 & 85 & 26 \\
Wang $^{(24)}$ & 1981 & 35 & 86 & 40 \\
Schaitkin $^{(25)}$ & 1981 & 17 & 76 & 47 \\
Simpson $^{(26)}$ & 1982 & 14 & 93 & 0 \\
Nair $^{(17)}$ & 1982 & 12 & 92 & 33 \\
Small $^{(1)}$ & 1984 & 16 & 100 & 38 \\
Premachandra $^{(9)}$ & 1992 & 23 & 100 & 26 \\
Assimakopoulos $^{(27)}$ & 1992 & 16 & 88 & 25 \\
\hline \multicolumn{5}{r}{} \\
\hline
\end{tabular}


Table 3. Results of articles reporting on endoscopic ligation (12 papers).

\begin{tabular}{lcccc}
\hline Author & Year & $\begin{array}{c}\text { Number } \\
\text { of patients }\end{array}$ & $\begin{array}{c}\text { Success } \\
\text { rate \% }\end{array}$ & $\begin{array}{c}\text { Complications } \\
\%\end{array}$ \\
\hline Sulsenti $^{(28)}$ & 1987 & 17 & 100 & 0 \\
Budrovich $^{(29)}$ & 1992 & 33 & 100 & 0 \\
Winstead $^{(30)}$ & 1996 & 10 & 90 & 0 \\
White $^{(31)}$ & 1996 & 2 & 100 & 0 \\
El-Guindy $^{(32)}$ & 1998 & 9 & 100 & 0 \\
Pritkin $^{(33)}$ & 1998 & 10 & 100 & 0 \\
Snyderman $^{(34)}$ & 1999 & 38 & 92 & 0 \\
Ram $^{(35)}$ & 2000 & 6 & 83 & 0 \\
O'Flynn $^{(14)}$ & 2000 & 12 & 100 & 0 \\
Wormwald $^{(36)}$ & 2000 & 13 & 92 & 0 \\
Cascio $^{(37)}$ & 2000 & 23 & 96 & 0 \\
Voegels $^{(38)}$ & 2001 & 11 & 100 & 0 \\
Abdelkader $^{(39)}$ & 2007 & 27 & 100 & 0 \\
\hline & \multicolumn{5}{c}{ Total=179 } & Mean=96.4\% & Mean $=0 \%$ \\
\hline
\end{tabular}

Table 4 Results of articles reporting on endoscopic cautery/diathermy (17 papers).

\begin{tabular}{|c|c|c|c|c|}
\hline Author & Year & $\begin{array}{c}\text { Number } \\
\text { of patients }\end{array}$ & $\begin{array}{c}\text { Success } \\
\text { rate } \%\end{array}$ & $\begin{array}{c}\text { Complications } \\
\% \\
\end{array}$ \\
\hline Anderson $^{(40)}$ & 1984 & 10 & 100 & 0 \\
\hline Borgstein ${ }^{(41)}$ & 1987 & 12 & 100 & 0 \\
\hline Wurman ${ }^{(42)}$ & 1988 & 18 & 67 & 6 \\
\hline Bingham $^{(43)}$ & 1991 & 2 & 100 & 0 \\
\hline McGarry ${ }^{(44)}$ & 1991 & 12 & 92 & 0 \\
\hline O'Leary- & 1992 & 6 & 83 & 0 \\
\hline \multicolumn{5}{|l|}{ Stickney ${ }^{(45)}$} \\
\hline Elwany ${ }^{(46)}$ & 1996 & 38 & 68 & 3 \\
\hline Kaluskar ${ }^{(47)}$ & 1996 & 18 & 100 & 0 \\
\hline Pollice ${ }^{(48)}$ & 1997 & 30 & 100 & 3 \\
\hline Rudert ${ }^{(49)}$ & 1997 & 31 & 97 & 0 \\
\hline Frikart ${ }^{(50)}$ & 1998 & 139 & 92 & 0 \\
\hline Srinivasan ${ }^{(51)}$ & 2000 & 10 & 90 & 0 \\
\hline Tsai ${ }^{(52)}$ & 2002 & 9 & 89 & 0 \\
\hline Prepageran ${ }^{(53)}$ & 2003 & 4 & 100 & 0 \\
\hline Wiorowski ${ }^{(54)}$ & 2004 & 10 & 90 & 0 \\
\hline Durr ${ }^{(55)}$ & 2004 & 17 & 94 & 0 \\
\hline Abdelkader ${ }^{(39)}$ & 2007 & 8 & 100 & 0 \\
\hline
\end{tabular}

All objective evidence from angiography and anatomical dissections, show substantial anastomosis between ipsilateral vessels only and there is no objective evidence of refilling of the nasal vessels from contralateral vessels. Many 'potential' routes do exist but refill very slowly. Angiographic work ${ }^{(18)}$ demonstrates that 'transmedian anastomoses are common but are insufficient for ensuring supply of the contralateral maxillary artery system but sufficient to demonstrate adjacent parts of the contralateral branches'. Late refilling several months to years after is a different matter and can be due to reperfusion from many sources (angiography) eg from the internal carotid artery, occipital arteries etc.
Thus ligation of a unilaterally small maxillary artery may be associated with a higher chance of failure because first order vessels will be larger and will reperfuse the bleeding point much more effectively and ligation of contralateral vessels in such cases would not be beneficial.

From an extensive literature review, endoscopic techniques seem to have a lower failure and complication rate compared to transantral ligation (table 2, 3 and 4). Transantral ligation has an average success rate of $91.3 \%$ compared to $96.4 \%$ and 91.9\% in endoscopic ligation and cautery respectively. Major complications with endoscopic techniques are near zero compared to an average of $20 \%$ in transantral ligation. However, it is inappropriate to draw too many conclusions from the simple analysis: some papers have very small numbers, some do not specifically mention complication rates whilst others also mention minor as well as major complications ${ }^{(34)}$ It could be argued that distal clipping occludes the flow at a level that is distal to most retrograde anastomotic connections making it theoretically more effective and logical ${ }^{(14)}$. The major difference between transantral and endoscopic may simply be improved identification of vessels or at least there is not an actual need to correctly identify specific vessels, to ensure that the correct vessels are treated correctly. Pearson suggested that there were ' 3 essential clips' ${ }^{(8)}$. Endoscopic ligation/ cautery is replacing transantral techniques in most centres ${ }^{(31,32)}$ in the treatment of persistent posterior epistaxis though more widespread usage particularly in the acute setting, is limited by the necessity of extra resources specialized equipment, appropriate staffing and experience.

The tightly packed arteries with a fragile thin-walled vein are vulnerable to damage during surgery involving the pterygopalatine fossa. Improved understanding of the arterial configuration within the fossa would allow safer surgical approaches when surgery is necessary for infections or neoplastic processes in this space or for access to the infratemporal fossa.

\section{CONCLUSION}

Care should be taken approaching dissection and identification of the vascular layer (thin vein and tightly packed arteries) of the pterygopalatine fossa. Although the configuration of the distal maxillary artery can be complex, it can be categorized for simplification into one of three subtypes, allowing the arterial anatomy of the pterygopalatine fossa to be more easily understood leading to safer surgery. Some configurations are more likely to lead to confusion particularly when combined with small posterior wall osteotomies.

More than one artery should be expected to exit from the pterygopalatine fossa into the nasal cavity via the sphenopalatine foramen, additional branches should be sought out specifically with careful dissection to reduce the chances of clipping/ cautery failing due to inadequate treatment. 
Asymmetry of the maxillary / sphenopalatine arteries is not common. Contralateral ligation / cautery is not indicated; generally, treating epistaxis by ligating / cauterizing vessels in the nose close to the bleeding point will be most effective.

\section{ACKNOWLEDGEMENTS}

I would like to give thanks to Dr Shaw-Dunn of the Laboratory of Human Anatomy, University of Glasgow for his support.

\section{REFERENCES}

1. Small M, Maran AGA. Epistaxis and arterial ligation. J Laryngol Otol 1984; 98: 281-284.

2. Kotecha B, Fowler S, Harkness P, Walsmsey J, Brown P, Topham J. Management of epistaxis: a national survey. Ann R Coll Surg Engl 1996; 78: 444-446.

3. Elahi MM, Parnes LS, Fox AJ, David M, Lee DH. Therapeutic embolization in the treatment of intractable epistaxis. Archives of Otolaryngol Head Neck Surg 1995; 121: 65-69.

4. Chandler JR, Serrins AJ. Transantral ligation of the internal maxillary artery for epistaxis. Laryngoscope 1965; 75: 1151-1159.

5. Rosnagle RS, Yanagisawa E, Smith HW. Specific ligation for epistaxis. Laryngoscope 1973; 83: 517-525.

6. Sulsenti G, Yanez C, Kadiri M. Recurrent epistaxis: microscopic endonasal clipping of the sphenopalatine artery. Rhinology 1987; 25: $141-142$.

7. Metson R, Lane R. Internal maxillary artery ligation for epistaxis. An analysis of failures. Laryngoscope 1988; 98: 760-764.

8. Pearson BW, MacKenzie RG, Goodman WS. The anatomical basis of transantral ligation of the maxillary artery in severe epistaxis. Laryngoscope 1969; 79: 969-984.

9. Premachandra DJ, Sergeant RJ. Dominant maxillary artery as a cause of failure in maxillary artery ligation for posterior epistaxis. Clin. Otolaryngol. 1993; 18: 42-47.

10. Morton $\mathrm{AL}$, Khan A. Internal maxillary artery variability in the pterygopalatine fossa. Otolaryngol Head Neck Surg 1991; 104: 204209.

11. Isaacs SJ, Goyal P. Endoscopic anatomy of the pterygopalatine fossa. Am J Rhinol 2007; 21: 644-647.

12. Wareing MJ, Padgham ND. Osteologic Classification of the Sphenopalatine foramen. Laryngoscope 1998; 108: 125-127.

13. Simmens DB, Raghavan U, Briner HR, Manestar M, Groscurth P, Jones NS. The anatomy of the sphenopalatine artery for the endoscopic sinus surgeon. Am J Rhinol 2006; 20: 502-505.

14. O'Flynn PE, Shadaba A. Management of posterior epistaxis by endoscopic clipping of the sphenopalatine artery. Clin Otol 2000; 25: 374-377.

15. Lasjaunias P, Berenstein A, Doyan D. Normal functional anatomy of the facial artery. Neuroradiology. 1979; 133: 631-638.

16. Moorthy R, Anand R, Prior M, Scott M. Inferior turbinate necrosis following Endoscopic sphenopalatine artery ligation. Otolaryngol Head Neck 2003; 129: 159-160.

17. Nair KK. Transantral ligation of the internal maxillary artery. Laryngoscope 1982; 92: 1060-1063.

18. Lasjaunias, P, Berenstein, A. Sugical neuroangiography Volume 1: Functional anatomy of Craniofacial Arteries. Springer Verlag. Berlin. 1987.

19. Singh B. Combined internal maxillary and anterior ethmoidal arterial occlusion: the treatment of choice in intractable epistaxis. J Laryngol Otol 1992; 106: 507-510.

20. Shaheen OH. Arterial epistaxis. J Laryngol Otol 1975; 89: 17-34.

21. Lofgren 1971 Lofgren RH. Surgery of the pterygomaxillary fossa. Arch Otol 1971; 94: 516-524.

22. Montgomery WW, Lofgren RH, Chaser WD. Analysis of pterygopalatine space surgery-1970. Laryngoscope 1970; 80: 1190-1200.

23. McDonald TJ, Pearson BW. Follow-up on maxillary artery ligation for epistaxis. Arch Otolaryngol 1980; 106: 635-638.
24. Wang L, Vogel DH. Posterior epistaxis: comparison of treatment. Otolaryngol Head Neck Surg 1981; 89: 1001-1006.

25. Schaitkin B, Strauss M, Houck JR. Epistaxis: medical versus surgical therapy: a comparison of efficacy, complications, and economic considerations. Laryngoscope 1981; 97: 1392-1396.

26. Simpson GT 2nd, Janfaza P, Becker GD. Transantral sphenopalatine ligation. Laryngoscope 1982; 92: 1001-1005.

27. Assimakopoulos D, Skevas A, Exarchacos G, Bliouras K. Our experience with surgical treatment of posterior epistaxis. Report of 16 cases. Rev Stomatol Chir Maxillofac 1992; 93: 273-277.

28. Sulsenti G, Yanez C, Kadiri M. Recurrent epistaxis: microscopic endoscopic clipping of the sphenopalatine artery. Rhinology 1987; 25: $141-142$.

29. Budrovich R, Saetti R. Microscopic and endoscopic ligature of the sphenopalatine artery. Laryngoscope 1992; 102: 1390-1394.

30. Winstead W. Sphenopalatine artery ligation: an alternative to internal maxillary ligation for intractable posterior epistaxis. Laryngoscope 1996; 106: 677-679.

31. White PS. Endoscopic ligation of the sphenopalatine artery: a preliminary description. J Laryngol Otol 1996; 110: 27-30.

32. El-Guindy A. Endoscopic transseptal sphenopalatine artery ligation for intractable posterior epistaxis. Ann Otol Rhinol Laryngol 1998; 107: 1033-1037.

33. Pritkin JB, Caldarelli DD, Panje WR. Endoscopic ligation of the internal maxillary artery for treatment of intractable posterior epistaxis. Ann Otol Rhinol Laryngol 1998; 107: 85-91.

34. Snyderman CH, Goldman SA, Carrau RL, Ferguson BJ, Grandis JR. Endoscopic sphenopalatine artery ligation is an effective method of treatment for posterior epistaxis. Am J Rhinol 1999; 13: 137-140.

35. Ram B, White PS, Saleh HA, Odutoye T, Cain A. Endoscopic endonasal ligation of the sphenopalatine artery. Rhinology 2000; 38: $147-149$.

36. Wormwald PJ, Wee DT, van Hasselt CA. Endoscopic ligation of the sphenopalatine artery for refractory posterior epistaxis. Am J Rhinol 2000; 14: 261-264.

37. Cascio F, Bucolo S, Quattrocchi C, Abbate G, Polimente G, Loteta G. Epistaxis: emergency treatment approach. Acta Otorhinolaryngol Ital 2000; 20: 424-431.

38. Voegels RL, Thome DC, Iturralde PP, Butugan O. Endoscopic ligature of the sphenopalatine artery for severe posterior epistaxis. Otolaryngol Head Neck Surg 2001; 124: 464-467.

39. Abdelkader M, Leong SC, White PS. Endoscopic control of the sphenopalatine artery for epistaxis: long term results. J Laryngol Otol 2007; 121: 759-762.

40. Anderson RG, Shannon DN, Schaefer SD, Raney LA. A surgical alternative to internal maxillary ligation for posterior epistaxis. Otolarygnol Head Neck Surg 1984; 92: 427-433.

41. Borgstein JA. Epistaxis and the flexible nasoendoscope. Clin Otol 1987; 12: 49-51.

42. Wurman LH, Sack JG, Flannery JV, Paulson TO. Selective endoscopic electrocautery for posterior epistaxis. Laryngoscope 1988; 98: 1348-1349.

43. Bingham B, Dingle AF. Endoscopic management of severe epistaxis. JLO 1991; 20: 442-443.

44. McGarry GW. Nasal endoscopy in posterior epistaxis: a preliminary evaluation. JLO 1991; 105: 428-434.

45. O’Leary-Stickney K, Makielski K, Weymuller EA. Rigid endoscopy for the control of epistaxis. Arch Otolaryngol Head Neck Surg 1992; 118: 966-967.

46. Elwany S, Abdel-Fatah H. Endoscopic control of posterior epistaxis. J Laryngol Otol 1996; 110: 432-434.

47. Kaluskar SK. Endoscopic approach to posterior epistaxis. Min Invas Ther and Allied Technol. 1996; 5: 75-77.

48. Pollice PA, Yoder MG. Epistaxis: a retrospective review of hospitalized patients. Otolarygnol Head Neck Surg 1997; 117: 49-53.

49. Rudert H, Maune S. Endoscopic coagulation of the sphenopalatine artery in severe posterior epistaxis. Laryngorhinootologie 1997; 76: $77-82$. 
50. Frikart L, Agrifoglio A. Endoscopic treatment of posterior epistaxis. Rhinology 1998; 36: 59-61.

51. Srinivasan V, Sherman IW, O'Sullivan G. Surgical management of intractable epistaxis: audit of results. J Laryngol Otol 2000; 114: 697-700.

52. Tsai HM, Shu CH. Transnasal sphenopalatine artery electrocautery for posterior epistaxis. Zhonghua Yi Xue Za Zhi 2002; 65: 529-533.

53. Prepageran N, Krishnan G. Endoscopic coagulation of sphenopalatine artery for posterior epistaxis. Singapore Med J 2003; 44: 123125.

54. Wiorowski M, Schultz P, Perrot JB, Gentine A, Debry C. Indications and results of cauterization by endoscopic approach of the sphenopalatine artery in severe posterior epistaxis. Auris Nasus Larynx 2004; 31: 131-133.
55. Durr DG. Endoscopic electrosurgical management of posterior epistaxis: shifting paradigm. J Otolaryngol 2004; 33: 211-216.

Tor Chiu

Plastic Reconstructive Surgery

Department of Surgery

The Chinese University of Hong Kong

Prince of Wales Hospital

Hong Kong

Tel: +852-263 22639

Fax: +852-263 77974

E-mail: torchiu@clara.co.uk

\section{UCL EAR INSTITUTE \\ GRAYS INN ROAD COURSES}

\section{IIIII}

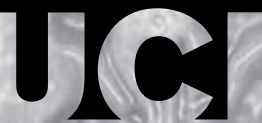

An Endoscopic Approach

to Rhinosinusitis

7-10 October

\section{9}

Course Faculty:

V J Lund, D Roberts, J Rowe-Jones

L Badia, S Durham, T Beale

Guest Lecturer: Professor Heinz Stammberger

The course covers all aspects of rhinosinusitis, advanced approaches to the frontal sinus including balloon sinuplasty, extended endoscopic surgery of the skull base and orbit and the use of computer assisted surgery from a very experienced faculty using:
Hands-on anatomy dissection with powered instrumentation
Anatomical demonstrations
Live operating
At The Royal National Thro Nose \& Ear Hospital Free Hampstead NHS Trust) and the UCL Ear Institute

- Lectures \& discussion

\section{Visit: www.ucl.ac.uk/ear/training}

\section{Registration:}

$£ 799.00$ - including dissection (limited spaces) $\quad £ 459.00$ - without dissection ERS Members are entitled to a $10 \%$ discount 